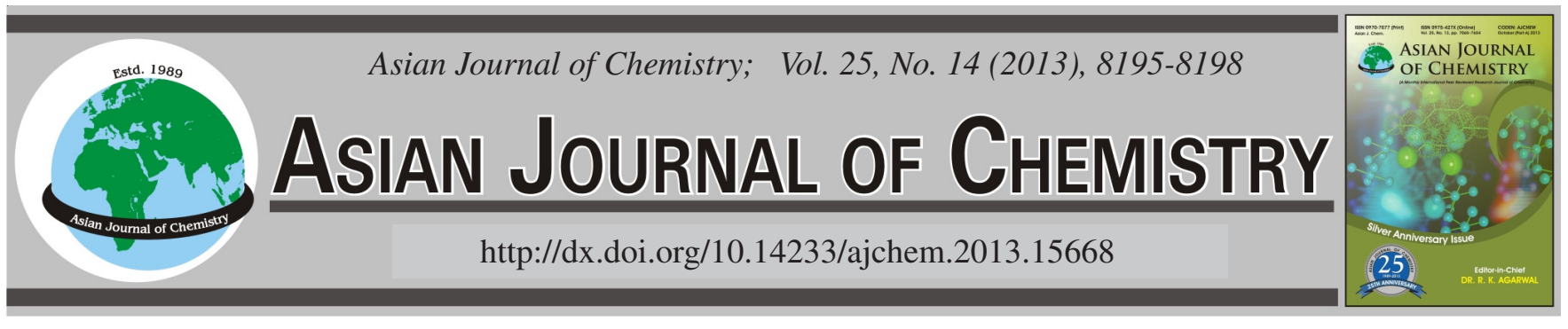

\title{
Synthesis and Spectroscopic Studies of Schiff Base and Its Divalent and Trivalent Metal Complexes
}

\author{
VANDNA Singh ${ }^{*}$ and UPMa Singh
}

Department of Applied Chemistry, School of Vocational Studies and Applied Sciences, Gautam Buddha University, Greater Noida-201 308, India *Corresponding author: E-mail: malikvandna@gmail.com

\begin{abstract}
A new macrocyclic ligand is prepared by refluxing isatin and 2,6-diamino-4-chloropyrimidine in methanolic medium with the m.f. $\mathrm{C}_{24} \mathrm{H}_{12} \mathrm{~N}_{8} \mathrm{Cl}_{2}$. The complexes are synthesized by template condensation of isatin and 2,6-diamino-4-chloropyrimidine in methanolic medium in the presence of divalent nickel, copper, zinc salts and trivalent chromium, iron salts and may be represented by formula:

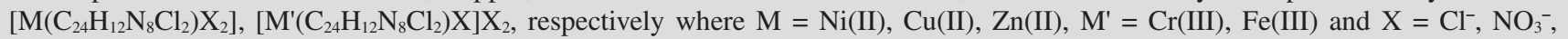
$\mathrm{CH}_{3} \mathrm{COO}^{-}$. The ligand coordinates through all four azomethine nitrogens but heterocyclic nitrogens do not take part in coordination as confirmed by absence of (M-pyrimidine) vibrations. These complexes have been characterized with the help of various physico-chemical techniques like IR, far-IR, NMR, elemental analyses, electronic spectra, conductance and magnetic susceptibilities. The distorted octahedral geometry has been proposed for divalent metal complexes and a five-coordinate distorted square pyramidal geometry for trivalent metal ion complexes.
\end{abstract}

Key Words: Macrocyclic ligand, Isatin, 2,6-Diamino-4-chloropyrimidine.

ᄂ - - - - - - - - - - - - - - -

\section{INTRODUCTION}

Transition metal ions play an important role in the development of new molecular materials which show magnetic properties and find applications in various fields. During the past few decades, the synthesis of macrocyclic complexes has been a fascinating area of research growing at a fast pace, owing to their resemblance to naturally occurring macrocycles and analytical, industrial and medicinal applications ${ }^{1-4}$. Synthetic macrocyclic complexes may mimic some naturally occurring macrocycles because of their resemblance with many natural macrocycles like metalloproteins, porphyrins and cobalamines. Transition metal macrocyclic complexes have received a great attention because of their biological activities, including antiviral, antcarcinogenic, antifertile, antibacterial and antifungal. Macrocyclic metal complexes of lanthanide e.g., $\mathrm{Gd}^{3+}$ are used as magnetic resonance imaging (MRI) contrast agents $^{5-9}$. A number of nitrogen donor macrocyclic derivatives have long been used in analytical, industrial and medical applications ${ }^{10}$. In the present paper, the synthesis and characterization of macrocyclic ligand prepared by isatin and 2,6-diamino-4-chloropyrimidine and its complexes with divalent nickel, copper, zinc salts and trivalent chromium, iron salts have been discussed.

EXPERIMENTAL

2,6-Diamino-4-chloropyrimidine and isatin was purchased from Koch-Light, England. All other chemicals used were of AnalR grade.

Isolation of ligand: Ligand was prepared by refluxing isatin and 2,6-diamino-4-chloropyrimidine in methanolic medium solution was refluxed for $8 \mathrm{~h}$. On overnight cooling dark coloured ppt. formed which was filtered, washed with methanol, acetone, diehtylether and dried in vacuo. (Yield $45 \%$ ). The ligand was found soluble in DMF and DMSO, but insoluble in common organic solvents and water. The syntheses of the ligand may be represented by the following Scheme-I:

Isolation of the metal complexes: All the transition metal complexes were obtained by template synthesis. To a stirring methanolic solution $\left(\mathrm{ca} .50 \mathrm{~cm}^{3}\right.$ ) of 2,6-diamino-4-chloropyrimidine $(10 \mathrm{mmol})$ was added divalent nickel, copper, zinc and trivalent chromium and iron salt $(5 \mathrm{mmol})$ dissolved in minimum quantity of methanol $\left(20 \mathrm{~cm}^{3}\right)$. The resulting solution was refluxed for $0.5 \mathrm{~h}$. After that isatin $(10 \mathrm{mmol})$ dissolved in $c a .20 \mathrm{~cm}^{3}$ methanol added in the refluxing mixture and again refluxed for 8-10 h. On overnight cooling dark coloured precipitate. formed which was filtered, washed with methanol, acetone, diehtylether and dried in vacuo (yield $45 \%$ ). All the complexes were found soluble in DMF and DMSO, but were 
<smiles>Nc1cc(Cl)nc(N)n1</smiles>

Scheme-I

insoluble in common organic solvents and water. They were thermally stable up to $c a .250^{\circ} \mathrm{C}$ and then decomposed.

The template syntheses of the complexes may be represented by the following scheme:

$$
\mathrm{C}_{8} \mathrm{H}_{5} \mathrm{O}_{2} \mathrm{~N}+\mathrm{C}_{4} \mathrm{H}_{5} \mathrm{~N}_{4} \mathrm{Cl}+\mathrm{MX}_{2} \underset{(6-8 \mathrm{~h})}{\stackrel{\text { Reflux in methanol }}{\longrightarrow}}
$$

$$
\left[\mathrm{M}\left(\mathrm{C}_{24} \mathrm{H}_{12} \mathrm{~N}_{8} \mathrm{Cl}_{2}\right) \mathrm{X}_{2}\right]+4 \mathrm{H}_{2} \mathrm{O}
$$

where $\mathrm{M}=\mathrm{Co}(\mathrm{II}), \mathrm{Ni}(\mathrm{II}), \mathrm{Cu}(\mathrm{II})$ and $\mathrm{Zn}(\mathrm{II}) . \mathrm{X}=\mathrm{Cl}^{-}, \mathrm{NO}_{3}^{-}$, $\mathrm{CH}_{3} \mathrm{COO}^{-}$.

$$
\begin{aligned}
\mathrm{C}_{8} \mathrm{H}_{5} \mathrm{O}_{2} \mathrm{~N}+\mathrm{C}_{4} \mathrm{H}_{5} \mathrm{~N}_{4} \mathrm{Cl}+\mathrm{MX}_{2} \frac{\text { Reflux in methanol }}{(6-8 \mathrm{~h})} \\
{\left[\mathrm{M}\left(\mathrm{C}_{24} \mathrm{H}_{12} \mathrm{~N}_{8} \mathrm{Cl}_{2}\right) \mathrm{X}\right] \mathrm{X}_{2}+4 \mathrm{H}_{2} \mathrm{O} }
\end{aligned}
$$

where $\mathrm{M}=\mathrm{Cr}$ (III) and $\mathrm{Fe}(\mathrm{III}), \mathrm{X}=\mathrm{Cl}^{-}, \mathrm{NO}_{3}^{-}, \mathrm{CH}_{3} \mathrm{COO}^{-}$.

Analytical and physical measurements: The microanalyses of C, H and N were carried out at Sophisticated Analytical Instrument Facility, CDRI, Lucknow. The metal contents were determined by standard EDTA methods. Electronic spectra (DMF) were recorded on Cary 14 spectrophotometer. The magnetic susceptibility measurements were carried at IIT Roorkee. The IR spectra were recorded on Infrared spectrophotometer in the range $4000-200 \mathrm{~cm}^{-1}$ using $\mathrm{KBr}$ pellets. The NMR spectra were recorded on Bruker NMR spectrometer (300 MHz). The conductivity was measured on digital conductivity meter (HPG System, G-3001).

\section{RESULTS AND DISCUSSION}

The analytical data of ligand, divalent and trivalent macrocyclic complexes derived from 2,6-diamino-4-chloropyrimidine and isatin and the complexes formulated as: $\mathrm{C}_{24} \mathrm{H}_{12} \mathrm{~N}_{8} \mathrm{Cl}_{2},\left[\mathrm{M}\left(\mathrm{C}_{24} \mathrm{H}_{12} \mathrm{~N}_{8} \mathrm{Cl}_{2}\right) \mathrm{X}_{2}\right]$ and $\left[\mathrm{M}^{\prime}\left(\mathrm{C}_{24} \mathrm{H}_{12} \mathrm{~N}_{8} \mathrm{Cl}_{2}\right) \mathrm{X}\right] \mathrm{X}_{2}$, respectively where $\mathrm{M}=\mathrm{Ni}(\mathrm{II}), \mathrm{Cu}(\mathrm{II}), \mathrm{Zn}(\mathrm{II}), \mathrm{M}^{\prime}=\mathrm{Cr}(\mathrm{III})$, $\mathrm{Fe}(\mathrm{III})$ and $\mathrm{X}=\mathrm{Cl}^{-}, \mathrm{NO}_{3}{ }^{-}, \mathrm{CH}_{3} \mathrm{COO}^{-}$. Ligand and all the macrocyclic complexes are dark coloured solids and are soluble in dimethyl formamide or dimethyl sulphoxide. Conductivity measurement of divalent metal ion complexes in dimethyl sulphoxide indicated them to be non-electrolyte $\left(10-20 \mathrm{ohm}^{-1}\right.$ $\left.\mathrm{cm}^{2} \mathrm{~mol}^{-1}\right)^{11}$. The test for anions is positive only after decomposing the complexes, indicating their presence inside the coordination sphere. The anions test for trivalent metal ion complexes is positive before and after decomposing the complexes, indicating their presence inside as well as outside the coordination sphere. The higher values of molar conductance in dimethylsulphoxide indicate them to be 1:2 electrolytic in nature $\left(140-150 \mathrm{ohm}^{-1} \mathrm{~cm}^{2} \mathrm{~mol}^{-1}\right)^{12}$. All compounds give satisfactory elemental analyses results as shown in the Table-1. All complexes were decomposed over $250{ }^{\circ} \mathrm{C}$ indicating their thermal stability.

IR Spectra: It was noted that a pair of bands are present in the spectrum of 2,6-diamino-4-chloropyrimidine at 3400$3200 \mathrm{~cm}^{-1}$ corresponding to $\mathrm{v}\left(\mathrm{NH}_{2}\right)$ but are absent in the infrared spectra of ligand and all the complexes. Further, no strong absorption band was observed at $1735 \mathrm{~cm}^{-1}$ indicating the absence of $v(\mathrm{C}-\mathrm{O})$ group of isatin. This confirms the condensation of carbonyl groups of isatin and amino groups of 2,6diamino-4-chloropyrimidine. These results provide strong evidence for the formation of macrocyclic frame ${ }^{13-16}$. A strong absorption band in the region $1615-1595 \mathrm{~cm}^{-1}$ may be due to the $\mathrm{C}=\mathrm{N}$ group. The lower values of $\mathrm{v}(\mathrm{C}=\mathrm{N})$ may be explained on the basis of drift of lone pair density of azomethine nitrogen towards metal atom ${ }^{14-17}$. The presence of single medium intensity band in the region $3250 \mathrm{~cm}^{-1}$ in the isatin complexes may be assigned due to $\mathrm{v}(\mathrm{N}-\mathrm{H})$ stretching ${ }^{18}$. The bands present in the range $3050-3010 \mathrm{~cm}^{-1}$ may be assigned due to $\mathrm{v}(\mathrm{C}-\mathrm{H})$ stretching vibrations of aromatic moiety of isatin ${ }^{19,20}$. The various absorption bands in the region $1590-1400 \mathrm{~cm}^{-1}$ may be assigned due to $\mathrm{v}(\mathrm{C}=\mathrm{C})$ aromatic stretching vibrations of the aromatic ring of isatin moiety ${ }^{19,20}$. The bands present in the range $1350-1000 \mathrm{~cm}^{-1}$ are assigned due to $v(\mathrm{C}-\mathrm{N})$ vibration. The unchanged 2,6-diamino-4-chloropyrimidine ring vibrations occurring at 1610-1595, 1585-1565, 1485-1450 and $1440-1435 \mathrm{~cm}^{-1}$ of pyrimidine ring ruling out the possibility of 2,6-diamino-4-chloropyrimidine nitrogen coordination towards metal atom ${ }^{21}$. The IR spectra of the complexes do not show any change in the 2,6-diamino-4-chloropyrimidine ring vibrations and interestingly enough, it appears that in these complexes 2,6-diamino-4-chloropyrimidine nitrogen does not take part in coordination ${ }^{21}$. Thus in the presence of metal salts, a quadridentate macrocycle is formed which coordinates through azomethine nitrogen while 2,6-diamino-4-chloropyrimidine nitrogen does not take part in coordination. Moreover, the coordination through 2,6-diamino-4-chloropyrimidine nitrogen does not take place, as it will result in the formation of unstable four membered rings. Infrared spectra of nitrato complexes display threes $v(\mathrm{~N}-\mathrm{O})$ stretching bands at 1455$1410 \mathrm{~cm}^{-1}\left(v_{5}\right), 1315-1305 \mathrm{~cm}^{-1}\left(v_{1}\right)$ and $1030-1015 \mathrm{~cm}^{-1}\left(v_{2}\right)$. The separation of two highest frequency bands $\left(v_{5}-v_{1}\right)$, 
TABLE-1

ANALYTICAL DATA OF DIVALENT NICKEL, COPPER AND TRIVALENT CHROMIUM AND IRON COMPLEXES DERIVED FROM 2,6-DIAMINO-4-CHLOROPYRIMIDINE AND ISATIN. FOUND (CALCD.) \%

\begin{tabular}{|c|c|c|c|c|c|c|c|c|c|}
\hline S. No & Complexes & M & $\mathrm{C}$ & $\mathrm{H}$ & $\mathrm{N}$ & $\mathrm{Cl}$ & Colour & m.w. & $\begin{array}{l}\text { Cond. } \\
\left(\Omega^{-1}\right)\end{array}$ \\
\hline 1 & $\mathrm{C}_{24} \mathrm{H}_{12} \mathrm{~N}_{8} \mathrm{Cl}_{2}$ & - & $\begin{array}{c}59.60 \\
(59.63)\end{array}$ & $\begin{array}{c}2.49 \\
(2.48)\end{array}$ & $\begin{array}{l}23.18 \\
(23.19)\end{array}$ & $\begin{array}{c}14.73 \\
(14.70)\end{array}$ & Light yellow & 483.00 & - \\
\hline 2 & {$\left[\mathrm{Ni}\left(\mathrm{C}_{24} \mathrm{H}_{12} \mathrm{~N}_{8} \mathrm{Cl}_{2}\right) \mathrm{Cl}_{2}\right]$} & $\begin{array}{l}9.56 \\
(9.54)\end{array}$ & $\begin{array}{c}47.03 \\
(47.01)\end{array}$ & $\begin{array}{c}1.98 \\
(1.96)\end{array}$ & $\begin{array}{l}18.27 \\
(18.28)\end{array}$ & $\begin{array}{c}23.19 \\
(23.18)\end{array}$ & Blackish brown & 612.69 & 14 \\
\hline 3 & {$\left[\mathrm{Ni}\left(\mathrm{C}_{24} \mathrm{H}_{12} \mathrm{~N}_{8} \mathrm{Cl}_{2}\right)\left(\mathrm{NO}_{3}\right)_{2}\right]$} & $\begin{array}{c}8.83 \\
(8.82)\end{array}$ & $\begin{array}{c}43.27 \\
(43.26)\end{array}$ & $\begin{array}{c}1.82 \\
(1.80)\end{array}$ & $\begin{array}{l}21.02 \\
(21.03)\end{array}$ & $\begin{array}{c}10.66 \\
(10.67)\end{array}$ & Light grey & 665.69 & 16 \\
\hline 4 & {$\left[\mathrm{Ni}\left(\mathrm{C}_{24} \mathrm{H}_{12} \mathrm{~N}_{8} \mathrm{Cl}_{2}\right)(\mathrm{OAc})_{2}\right]$} & $\begin{array}{c}8.93 \\
(8.90)\end{array}$ & $\begin{array}{c}50.90 \\
(50.93)\end{array}$ & $\begin{array}{c}2.70 \\
(2.73)\end{array}$ & $\begin{array}{c}16.96 \\
(16.98)\end{array}$ & $\begin{array}{c}10.78 \\
(10.76)\end{array}$ & Dark green & 659.69 & 15 \\
\hline 5 & {$\left[\mathrm{Cu}\left(\mathrm{C}_{24} \mathrm{H}_{12} \mathrm{~N}_{8} \mathrm{Cl}_{2}\right) \mathrm{Cl}_{2}\right]$} & $\begin{array}{c}10.24 \\
(10.28)\end{array}$ & $\begin{array}{c}46.63 \\
(46.64)\end{array}$ & $\begin{array}{c}1.97 \\
(1.94)\end{array}$ & $\begin{array}{l}18.13 \\
(18.14)\end{array}$ & $\begin{array}{l}23.03 \\
(23.00)\end{array}$ & Yellow & 617.50 & 10 \\
\hline 6 & {$\left[\mathrm{Cu}\left(\mathrm{C}_{24} \mathrm{H}_{12} \mathrm{~N}_{8} \mathrm{Cl}_{2}\right)\left(\mathrm{NO}_{3}\right)_{2}\right]$} & $\begin{array}{c}9.49 \\
(9.47)\end{array}$ & $\begin{array}{c}42.99 \\
(42.95)\end{array}$ & $\begin{array}{c}1.72 \\
(1.79)\end{array}$ & $\begin{array}{l}20.85 \\
(20.88)\end{array}$ & $\begin{array}{l}10.57 \\
(10.59)\end{array}$ & Mustard & 670.50 & 12 \\
\hline 7 & {$\left[\mathrm{Cu}\left(\mathrm{C}_{24} \mathrm{H}_{12} \mathrm{~N}_{8} \mathrm{Cl}_{2}\right)(\mathrm{OAc})_{2}\right]$} & $\begin{array}{l}9.53 \\
(9.56)\end{array}$ & $\begin{array}{c}50.58 \\
(50.56)\end{array}$ & $\begin{array}{c}2.75 \\
(2.71)\end{array}$ & $\begin{array}{l}16.86 \\
(16.85)\end{array}$ & $\begin{array}{c}10.66 \\
(10.68)\end{array}$ & Dark yellow & 664.50 & 20 \\
\hline 8 & {$\left[\mathrm{Cr}\left(\mathrm{C}_{24} \mathrm{H}_{10} \mathrm{~N}_{6}\right) \mathrm{Cl}\right] \mathrm{Cl}_{2}$} & $\begin{array}{c}8.13 \\
(8.11)\end{array}$ & $\begin{array}{c}44.87 \\
(44.89)\end{array}$ & $\begin{array}{c}1.85 \\
(1.87)\end{array}$ & $\begin{array}{l}17.47 \\
(17.46)\end{array}$ & $\begin{array}{c}27.68 \\
(27.67)\end{array}$ & Light brown & 641.50 & 144 \\
\hline 9 & {$\left[\mathrm{Cr}\left(\mathrm{C}_{24} \mathrm{H}_{12} \mathrm{~N}_{8} \mathrm{Cl}_{2}\right)\left(\mathrm{NO}_{3}\right)\right]\left(\mathrm{NO}_{3}\right)_{2}$} & $\begin{array}{c}7.24 \\
(7.22)\end{array}$ & $\begin{array}{c}39.96 \\
(39.94)\end{array}$ & $\begin{array}{c}1.68 \\
(1.66)\end{array}$ & $\begin{array}{l}21.35 \\
(21.36)\end{array}$ & $\begin{array}{l}9.81 \\
(9.85)\end{array}$ & Grey & 721.00 & 149 \\
\hline 10 & {$\left[\mathrm{Cr}\left(\mathrm{C}_{24} \mathrm{H}_{12} \mathrm{~N}_{8} \mathrm{Cl}_{2}\right)(\mathrm{OAc})\right](\mathrm{OAc})_{2}$} & $\begin{array}{l}7.33 \\
(7.30)\end{array}$ & $\begin{array}{c}50.57 \\
(50.56)\end{array}$ & $\begin{array}{c}2.98 \\
(2.95)\end{array}$ & $\begin{array}{l}15.70 \\
(15.73)\end{array}$ & $\begin{array}{l}9.95 \\
(9.97)\end{array}$ & Yellowish green & 712.00 & 143 \\
\hline 11 & {$\left[\mathrm{Fe}\left(\mathrm{C}_{24} \mathrm{H}_{12} \mathrm{~N}_{8} \mathrm{Cl}_{2}\right) \mathrm{Cl}\right] \mathrm{Cl}_{2}$} & $\begin{array}{c}8.62 \\
(8.60)\end{array}$ & $\begin{array}{c}44.66 \\
(44.65)\end{array}$ & $\begin{array}{c}1.87 \\
(1.86)\end{array}$ & $\begin{array}{c}17.34 \\
(17.36)\end{array}$ & $\begin{array}{c}27.50 \\
(27.52)\end{array}$ & Blackish brown & 645.00 & 140 \\
\hline 12 & {$\left[\mathrm{Fe}\left(\mathrm{C}_{24} \mathrm{H}_{12} \mathrm{~N}_{8} \mathrm{Cl}_{2}\right)\left(\mathrm{NO}_{3}\right)\right]\left(\mathrm{NO}_{3}\right)_{2}$} & $\begin{array}{l}7.68 \\
(7.66)\end{array}$ & $\begin{array}{c}39.73 \\
(39.75)\end{array}$ & $\begin{array}{c}1.64 \\
(1.66)\end{array}$ & $\begin{array}{l}21.28 \\
(21.26)\end{array}$ & $\begin{array}{c}9.82 \\
(9.80)\end{array}$ & Dark blue & 724.50 & 147 \\
\hline 13 & {$\left[\mathrm{Fe}\left(\mathrm{C}_{24} \mathrm{H}_{12} \mathrm{~N}_{8} \mathrm{Cl}_{2}\right)(\mathrm{OAc})\right](\mathrm{OAc})_{2}$} & $\begin{array}{l}7.75 \\
(7.76)\end{array}$ & $\begin{array}{c}50.34 \\
(50.310\end{array}$ & $\begin{array}{c}2.92 \\
(2.94)\end{array}$ & $\begin{array}{l}15.62 \\
(15.65)\end{array}$ & $\begin{array}{c}9.91 \\
(9.92)\end{array}$ & Orange & 715.50 & 145 \\
\hline 14 & {$\left[\mathrm{Zn}\left(\mathrm{C}_{24} \mathrm{H}_{12} \mathrm{~N}_{8} \mathrm{Cl}_{2}\right)(\mathrm{OAc})_{2}\right]$} & $\begin{array}{c}9.80 \\
(9.81)\end{array}$ & $\begin{array}{c}50.46 \\
(50.42)\end{array}$ & $\begin{array}{c}2.71 \\
(2.70)\end{array}$ & $\begin{array}{l}16.80 \\
(16.81)\end{array}$ & $\begin{array}{c}10.62 \\
(10.66)\end{array}$ & White & 666.34 & 14 \\
\hline
\end{tabular}

suggest that both the nitrate groups are coordinate in unidentate manner ${ }^{22}$. The acetato complexes show two bands at 1640$1630 \mathrm{~cm}^{-1}\left(\mathrm{v}_{1}\right)$ and $1390-1380 \mathrm{~cm}^{-1}\left(\mathrm{v}_{2}\right)$. These indicate that the acetate group is coordinated and act as unidentate ${ }^{23}$.

Far IR spectra: The far IR spectra show bands in the region $450-425 \mathrm{~cm}^{-1}$ corresponding to $v(\mathrm{M}-\mathrm{N})$ vibrations ${ }^{24-26}$. The presence of bands in all complexes in $450-425 \mathrm{~cm}^{-1}$ region originate from (M-N) azomethine vibrational modes and gives idea about coordination of azomethine nitrogens ${ }^{27}$. The bands present at $315-300 \mathrm{~cm}^{-1}$ may be assigned as being due to $v(\mathrm{M}-\mathrm{Cl})$ vibrations ${ }^{24,26}$. The bands present at 255-225 $\mathrm{cm}^{-1}$ in all nitrato complexes are assignable to $\mathrm{v}(\mathrm{M}-\mathrm{O})$ vibrations ${ }^{24}$. However, the absence of various (M-pyrimidine) vibrations supports the non-involvement of 2,6-diamino-4chloropyrimidine nitrogens in coordination.

${ }^{1}$ H NMR spectra: The ${ }^{1} \mathrm{H}$ NMR spectrum of zinc(II) complex show multiplets at 7.2-7.8 ppm which may be assigned due to hydrogens of aromatic rings ${ }^{27-29}$. A broad singlet at 10.82 ppm may be assigned due to protons of the $\mathrm{NH}$ group of isatin ${ }^{30}$.

\section{Magnetic measurements and electronic spectra}

Chromium complexes: Magnetic moment of chromium complexes were found in the range of 4.25-4.50 BM at room temperature which is close to the predicted values for three unpaired electrons in the metal ion ${ }^{31}$. The electronic spectra of chromium(III) complexes show bands at 9030-9310, 13045$13335,17460-18320,27435-27830$ and $34815 \mathrm{~cm}^{-1}$. However, these spectral bands cannot be interpreted in terms of four- or six-coordinated environment around the metal atom. In turn, the spectral bands are consistent with that of five-coordinated chromium(III) complexes, whose structure have been confirmed with the help of X-ray measurements ${ }^{32}$. Thus keeping in view, the analytical data and electrolytic nature of these complexes, a five coordinated square pyramidal geometry may be assigned for these complexes. Thus, assuming the symmetry $\mathrm{C}_{4 \mathrm{~V}}$ for these complexes ${ }^{33}$, the various spectral bands may be assigned as: ${ }^{4} \mathrm{~B}_{1} \rightarrow{ }^{4} \mathrm{E}^{\mathrm{a}},{ }^{4} \mathrm{~B}_{1} \rightarrow{ }^{4} \mathrm{~B}_{2},{ }^{4} \mathrm{~B}_{1} \rightarrow{ }^{4} \mathrm{~A}_{2}$ and ${ }^{4} \mathrm{~B}_{1} \rightarrow{ }^{4} \mathrm{E}^{\mathrm{b}}$.

Iron complexes: The magnetic moment of iron complexes lie in the range 5.85-5.90 $\mathrm{BM}$ corresponding to the five unpaired electrons and is close to predicted high spin values for these metal ions ${ }^{31}$. The electronic spectra of iron(III) complexes show various bands at 9835-9960, 15530-15570, 27625$27730 \mathrm{~cm}^{-1}$ and are consistent with the range of spectral bands reported for five coordinate square pyramidal iron(III) complexes $^{34}$. Assuming $\mathrm{C}_{4 \mathrm{v}}$ symmetry for these complexes, the various bands can be assigned as: $\mathrm{d}_{\mathrm{xy}} \rightarrow \mathrm{d}_{\mathrm{xz}}, \mathrm{d}_{\mathrm{yz}}$ and $\mathrm{d}_{\mathrm{xy}} \rightarrow \mathrm{d}_{\mathrm{z}}^{2}$. Any attempt to make accurate assignment is difficult due to interactions of the metal-ligand $\pi$-bond systems lifting the degeneracy of the $d_{x z}$ and $d_{y z}$ pair.

Nickel complexes: The magnetic moment of nickel complexes at room temperature lie in the range 2.94-2.96 BM, in all the complexes. The solution spectra of $\mathrm{Ni}(\mathrm{II})$ complexes exhibit a well discernable band with a shoulder on the low energy side. The other two bands generally observed in the region at $16,660-17,050 \mathrm{~cm}^{-1}\left(\mathrm{~V}_{2}\right)$ and $27,850-28255 \mathrm{~cm}^{-1}\left(\mathrm{~V}_{3}\right)$, may be assigned to ${ }^{3} \mathrm{~A}_{2} \rightarrow{ }^{3} \mathrm{~T}_{1 \mathrm{~g}}(\mathrm{~F})\left(\mathrm{V}_{2}\right)$ and $3 \mathrm{~A}_{2 \mathrm{~g}} \rightarrow{ }^{3} \mathrm{~T}_{1 \mathrm{~g}}(\mathrm{P})$ $\left(v_{3}\right)$, respectively. The first two bands result from the splitting of one band, $v_{1}$ and are in the range at 9730-10,320 and 11,740- 
$12,310 \mathrm{~cm}^{-1}$, which can be assigned to ${ }^{3} \mathrm{~B}_{1 \mathrm{~g}} \rightarrow{ }^{3} \mathrm{E}_{\mathrm{g}}$ and ${ }^{3} \mathrm{~B}_{1 \mathrm{~g}} \rightarrow{ }^{3} \mathrm{~B}_{2 \mathrm{~g}}$, assuming the effective symmetry to be $\mathrm{D}_{4 \mathrm{~h}}$ (component of $3 \mathrm{~T}_{2 \mathrm{~g}}$ in $\mathrm{O}_{\mathrm{h}}$ symmetry $)^{35}$. The intense higher energy band at 34,510 $\mathrm{cm}^{-1}$ may be due to a $\pi-\pi *$ transition of the $(\mathrm{C}=\mathrm{N})$ group. Various bands do not follow any regular pattern and seem to be anion independent. The spectra are consistent with distorted octahedral nature of these complexes.

Copper complexes: The magnetic moments of copper complexes lay in the range 1.75-1.78 BM. The absorption spectra of the copper complexes exhibit bands in the region $17,520-19,625 \mathrm{~cm}^{-1}$ with a shoulder on the low energy side at $14,540-16,000 \mathrm{~cm}^{-1}$ and show that these complexes are distorted octahedral ${ }^{34}$. Assuming tetragonal distortion in the molecule, the d-orbital energy level sequence for these complexes may be: $x^{2}-y^{2}>z^{2}>x y>x z>y z$ and the shoulder can be assigned to: $z^{2} \rightarrow x^{2}-y^{2}\left({ }^{2} B_{1 g} \rightarrow{ }^{2} B_{2 g}\right)$ and the broad band contains both the $\mathrm{xy} \rightarrow \mathrm{x}^{2}-\mathrm{y}^{2}\left({ }^{2} \mathrm{~B}_{1 \mathrm{~g}} \rightarrow{ }^{2} \mathrm{E}_{\mathrm{g}}\right)$ and $\mathrm{xz}, \mathrm{yz} \rightarrow \mathrm{x}^{2}-\mathrm{y}^{2}$ $\left({ }^{2} \mathrm{~B}_{1 \mathrm{~g}} \rightarrow{ }^{2} \mathrm{~A}_{2 \mathrm{~g}}\right)$ transitions ${ }^{36}$. The band separation of the spectra of the complexes is of the order $2980 \mathrm{~cm}^{-1}$, which is consistent with proposed geometry of the complexes ${ }^{36}$. Therefore, it may be concluded that all the complexes of $\mathrm{Cu}$ (II) metals of this series are distorted octahedral.

\section{Conclusion}

Based on various physicochemical studies like elemental analyses, conductivity measurements, magnetic measurements, electronic and IR spectral studies, a distorted octahedral geometry may be proposed for all of divalent metal complexes as shown in Fig. 1 and five coordinate square pyramidal geometry for all trivalent metal complexes as shown in Fig. 2.

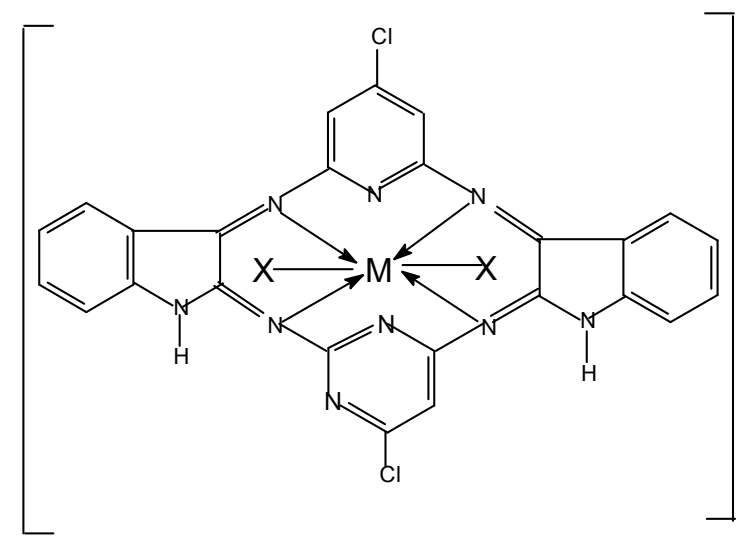

Fig. 1

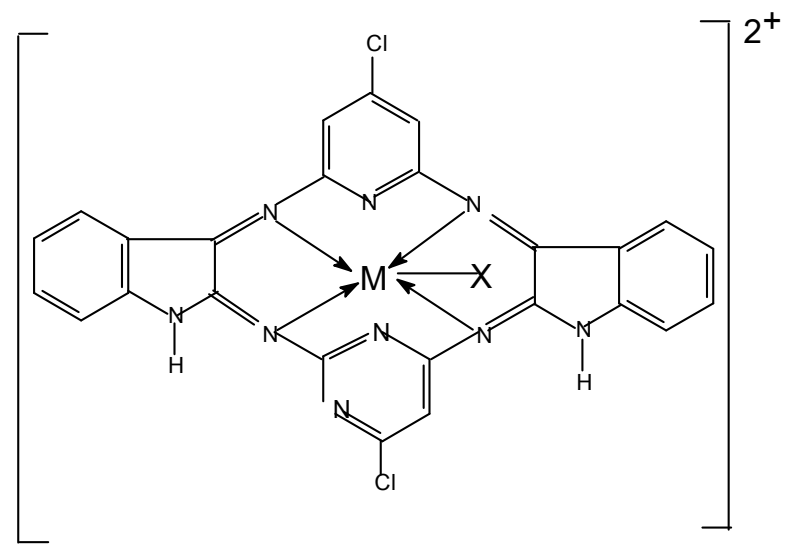

Fig. 2

\section{REFERENCES}

1. K. Gloe, Macrocyclic Chemistry: Current Trends and Future Perspectives, Dordrecht: Springer (2005).

2. L.F. Lindoy, The Chemistry of Macrocyclic Ligand Complexes, Cambridge University Press, Cambridge (1989).

3. E.C. Constable, Coordination Chemistry of Macrocyclic Compounds, Oxford: Oxford University Press (1999).

4. D.P. Singh, R. Kumar, V. Malik and P. Tyagi, Transition Met. Chem., 32, 1051 (2007).

5. M. Shakir, S. Khatoon, S. Parveen and Y. Azim, Transition Met. Chem., 32, 42 (2007); S. Chandra and S. Sharma, J. Indian Chem. Soc., 83, 988 (2006).

6. R.N. Prasad and A. Upadhyay, J. Indian Chem. Soc., 83, 857 (2006); M.F. Tweedle and Y.M. Runge, Drugs Future, 17, 187 (1992).

7. O.D. Fox, M.G.B. Drew, E.J.S. Wilkinson and P.O. Beer, Chem. Commun., 319 (2000)

8. S. Chandra, R. Gupta, N. Gupta and S.S.Bawa, Transition Met. Chem., 31, 147 (2006).

9. S. Chandra, L.K. Gupta and S. Agrawal, Transition Met. Chem., 32, 558 (2007).

10. W. Ma, Y. Tian, S. Zhang and J. Wu, Transition Met. Chem., 31, 97 (2006).

11. S. Chandra and S.D. Sharma, Transition Met. Chem., 27, 732 (2002); R.N. Prasad and M. Sharma, J. Indian Chem. Soc., 84, 236 (2007).

12. R. Kumar and R. Singh, Turk. J. Chem., 30, 77 (2006).

13. D.P. Singh, R. Kumar and P. Tyagi, Transition Met. Chem., 31, 970 (2006).

14. P.R. Athappan and G. Rajagopal, Polyhedron, 15, 527 (1996).

15. Z.A. Siddiqi, M. Khan, M. Khalid and S. Kumar, Transition Met. Chem., 32, 927 (2007).

16. D.P. Singh, K. Kumar and C. Sharma, Eur. J. Med. Chem., 44, 3299 (2009).

17. S. Chandra and S.D. Sharma, Transition Met. Chem., 27, 732 (2002).

18. J.S. Casas, E.E. Castellano and M.C. Rodriguez, Inorg. Chim. Acta, 304, 283 (2000).

19. R.N. Prasad, M. Mathur and A. Upadhayay, J. Indian Chem. Soc., 84, 1204 (2007).

20. D.P. Singh, N. Shishodia, B.P. Yadav and V.B. Rana, J. Indian Chem. Soc., 81, 287 (2004).

21. D.P. Singh, N. Shishodia, B.P. Yadav and V.B. Rana, Polyhedron, 16, 2229 (1997).

22. S. Chandra and L.K. Gupta, Spectrochim. Acta A, 60, 2767 (2004); M. Shakir, S.P. Varkey and P.S. Hameed, Polyhedron, 12, 2775 (1993).

23. K. Nakamoto, Infrared \& Raman Spectra of Inorganic \& Coordination Compounds, Wiley Interscience Publication, Part B, edn. 5 (1997).

24. M. Shakir, K.S. Islam, A.K. Mohamed, M. Shagufta and S.S. Hasan, Transition Met. Chem., 24, 577 (1999).

25. F.M.A.M. Aqra, Transition Met. Chem., 24, 337 (1999).

26. Chandra and R. Kumar, Transition Met. Chem., 29, 269 (2004).

27. V.B. Rana, D.P. Singh, P. Singh and M.P. Teotia, Polyhedron, 1, 377 (1982).

28. S. Chandra and L.K. Gupta, J. Indian Chem. Soc., 82, 454 (2005).

29. V.B. Rana, D.P. Singh, P. Singh and M.P. Teotia, Transition Met. Chem., 7, 174 (1982).

30. D.P. Singh, R. Kumar, M. Kamboj, V. Grover and K. Jain, Russ. J. Coord. Chem., 34, 233 (2008).

31. B.N. Figgis and J. Lewis, Prog. Inorg. Chem., 6, 37 (1965).

32. J.S. Wood, Prog. Inorg. Chem., 16, 227 (1972).

33. D.P. Singh and V.B. Rana, Polyhedron, 14, 2901 (1995); D.P. Singh and R. Kumar, J. Serb. Chem. Soc., 72, 1069 (2007).

34. A.B.P. Lever, Inorganic Electronic Spectroscopy, Elsevier, Amsterdam, edn. 2 (1984).

35. D.N. Sathyanarayana, Electron Absorption Spectroscopy and Related Techniques, Universities Press, India, edn. 1 (2001).

36. A.B.P. Lever and E. Mantovani, Inorg. Chem., 10, 817 (1971). 